\title{
LA LÓGICA MEXICANA DE ANTONIO RUBIO: UNA NOTA HISTORICA
}

WALTER REDMOND

Universidad autonoma de Pugbla

Describimos en esta nota la génesis de la lógica de Antonio Rubio de Rueda (1548-1615), con atención especial a los materiales prefatorios de varias ediciones. ${ }^{1}$ El éxito extraordinario de esta obra en Europa en la primera mitad del siglo Xvir se debe principalmente a su contenido filosófico, pero consideramos aquí solamente el contexto histórico de su composición y publicación. ${ }^{2}$

Los Comentarios a toda la lógica de Aristóteles, llamados en algunas ediciones la Lógica mexicana, fueron la primera obra de Rubio ${ }^{3}$ y for-

1 Las cuatro ediciones que hemos examinado son: Alcalá, 1603 (Comentarii in Universam Aristotelis Dialectican...), la primera edición, Alcalá, 1610, Colonia, 1615, y Lyón, 1619 (incompleta). Habría que extender este análisis a todas las ediciones, pero éstas contienen documentos fundamentales para reconstruir la historia de la publicación de las obras de Rubio.

2 La actitud sobre la vigencia de la filosofía de Rubio y sus colegas dependerá de la postura ante la historia de la filosofía. Existe hoy en día un renovado interés en la escolástica, sobre todo en su lógica (véase la semántica de los mundos posibles de L. Molina, p. ej.), filosofía del lenguaje, ontología, y filosofia de la religión. Hay pocos escritos sobre la filosofía de Rubio. Larry Hickman, notando que una tesis de Rubio es una "anticipación notable" de la ontología actual, como ejemplo del "contacto entre la tradición de la que formaba parte la lógica de la América Latina colonial y el trabajo de nuestros contemporáneos no-escolásticos", afirmó: "creo que la pauta es clara: la ontologia escolástica tradicional tiene una riqueza que no perderemos dentro de poco tiempo" (ponencia, 1979). En su Modern Theories of Higher Level Predicates: Second Intentions in the Neuzeit (Munich: 1980), Hickman cita (pp. 53-54) un pasaje de Rubio como evidencia de que el objetivismo habia suplantado el psicologismo en la escolástica de su tiempo: "se ha recibido en uso que la intención primera y segunda [lenguaje objeto y metalenguaje] casi siempre se toman por [contenidos] objetivos y raras veces o nunca por [conceptos] formales [subjetivos]; la razón es que las ciencias no tratan principalmente de los conceptos formales sino los objetivos, los cuales son las cosas mismas que consideran..." Leibniz utiliza estas nociones escolásticas en su explicación de la identidad. Wilhelm Risse, en Die Logik der Neuzeit (Stuttgart-Bad Cannstadt: 1970), 1:399ss, destaca varias tesis de Rubio: la lógica descansa no en la metafísica sino en sus propias presuposiciones, la lógica estudia el sentido objetivo de los procedimientos científicos, los universales no difieren realmente de los individuos ni les están sujetos, siendo por ende de validez ilimitada, etc.

3 A03/illustrissimo. Hacemos referencia a estos textos prefatorios notando la pri- 
man parte de un proyecto filosófico que concibió, elaboró, y llevó a cabo sustancialmente en la Nueva España. La lógica de Rubio probablemente ha tenido más influjo en Europa que cualquier libro de filosofía escrito en América Latina."

Rubio, llamado por Risse "el más importante de los jesuitas españoles", 5 nació en Rueda, entró con los jesuitas a los 21 años después de estudiar tres años de filosofía en la universidad de Alcalá. ${ }^{\circ}$ Como jesuita estudió su cuarto año de filosofía y cuatro años de teología en la misma universidad. ${ }^{7}$ Como él mismo dice, vino a México como alumnus (1676), enseñó filosofía por cuatro años y teología por doce, obtuvo dos maestrías y dos doctorados en filosofia y teología de la universidad de México (1694), y entonces concibió su proyecto filosófico. ${ }^{8}$ Parece que dedicó el último tercio de su residencia de casi 25 años en México a la redacción de al menos una parte de su obra filosófica. ${ }^{\circ}$ Parcial-

mera letra del lugar de publicación (ver nota 1) y el año, más el incipit (por falta de paginación).

${ }_{4}$ Descartes, p. ej., leyó a Rubio (carta ccvii, Oeuvres de Descartes, París: 1899, 3:185). J. S. Beristáin, hablando de las ediciones europeas de las obras de Rubio, no exagera al decir: "eternizándose así en España, Alemania, y Francia la gloria de México, que dio a la Europa en un doctor de su academia uno de los mejores intérpretes del principe de los filósofos", Biblioteca Americana Septentrional (Amecameca: 1883), 3:71. Risse observa que las universidades españolas "enviaban a menudo sus mejores mentes a la universidad de México" y "la Lógica Mexicana repercutió en Europa, siendo asi el vínculo entre la filosofía europea y latinoamericana". (Comunicaciones personales.)

5 Obra citada, p. 399 .

6 Monumenta mexicana, 2:744, en Diccionario bio-bibliográfico de la compañia de Jesús en México, por $\hat{\mathrm{F}}$. Zambrano, preparado por J. Gutiérrez Casillas (México: 1973), 12:733 (en adelante citamos el tomo xii de este Diccionario, con la letra "D" seguida del número de la página). Archivo Romano SJ, mss 4:8-10, D730.

7 Ibid.

8 A03/auctoria. Embarcó el 16 de julio según J. E. Uriarte, Anónimos y seudónimos (Madrid: 1904, etc.), 2:34-5, n. 1587, D751, y llegó a México "por principios de septiembre" según F. J. Alegre, Historia de la provincia de la compañia de Jesús de Nueva España, ed. Burrus y Zubillaga (Roma: 1956), 1:194, A. Astráin, Historia de la compañia de Jestis en la asistencia de España (Madrid: 1909), D727, G. Decorme, La obra de los jesuitas mexicanos en la época de la colonia (El Paso: 1941), 1:176. En A03/auctoris Rubio dice que leyó filosofía en el programa trienal (praelectam trium annorum curriculo), y en una carta de 1584: "la ocupación en que la obediencia me ha puesto estos ocho años que he estado en esta tierra, han sido los cuatro en leer artes y los otros cuatro en leer una lección de teología esco. lástica...", Rubio-Aquaviva, México, 25 de octubre, Monumenta mexicana, 2:383-90, D743, párr. 4. Si daba su cuarto año de teologia en 1584, su último año como profesor de esta disciplina fue en 1592. Alegre dice en Historia, 1:205, que comenzó a impartir su curso de filosofía desde fines de octubre de 1577. Se otorgó la licencia para recibir el doctorado en filosofía y teologia en 1694, respuesta al memorial presentado a Aquaviva en octubre, D733 y 755, n. 49.

9 Alegre, Historia, 2:96: "cuasi todo el tiempo que estuvo en la América, lo habla ocupado en escribir el Curso de Filosofía peripatética que tenemos suyo", pero el trabajo más directo debió de comenzar después. En el memorial presentado a Aqua- 
mente para que Rubio pudiera cuidar su publicación, la provincia mexicana lo eligió procurador en 1599, misión que requería un viaje a Roma. ${ }^{10}$ Probablemente salió de México para Europa a principios de 1600 y luego pasó a España en 1602.11 Con el permiso del general de la compañía, pero con gran mortificación de la provincia mexicana, permaneció en Alcalá por el resto de su vida.12

Después de describir brevemente la lógica de Rubio y presentar unos apuntes sobre su carrera en México, introduciremos los materiales prefatorios y a base de ellos comentaremos los motivos del proyecto filosófico de Rubio y el resultado de su publicación. Agregaremos una corta reflexión e incluimos en un apéndice una traducción de documentos latinos del autor.

\section{La lógica de Rubio}

Hay al menos dos versiones de los comentarios lógicos de Rubio. La primera se editó por primera vez en Alcalá en 1603; la segunda, un compendio de la primera, apareció primero en Valencia en 1606 con el título: Comentarios más breves a toda la lógica de Aristóteles. ${ }^{13}$ El título Lógica mexicana parece encontrarse por primera vez en la edi.

viva en octubre de 1593, D734, se dice que Rubio "desea hazer un comentario" y en la biografia, D747, "nos consta" que Rubio ya lo preparaba en octubre de 1593. Para el lugar de Tepotzotlán y Pátzcuaro, ver Decorme, La obra, 1:35, A. Pérez Rivas, Crónica (México: 1896), 2:169, y F. Ayuso y J. Sánchez Baquero, notas a Fundación de los de la compañia de Jesús en Nueva España, D735. Rubio mismo dice (A03/auctoris) que concibió su proyecto filosófico después de enseñar la teología y recibir sus títulos académicos (Post..., concilium incidit). Debe notarse la coincidencia del fin de su actividad docente, su graduación académica, y su actividad literaria.

10 Fue electo el 4 de noviembre de 1599, Acta de la quinta congregación provin. cial, D735. En cuanto al motivo, ver la carta Aquaviva-Váez, Roma, 11 de marzo de 1602 .

11 "Este mismo año [1600 Rubio] fue a Roma", Monumenta mexicana, 3:669, D737. Hay una indicación de que salió "por el mes de abril de 1600", D737; en cambio Porrúa, Diccionario (México: 1964), p. 1240 y Decorme, La obra, 1:13 y 176, dan 1599 como el año de su partida. El general de la compañía dijo que habla salido de Roma para el 15 de abril de 1602, carta Aquaviva-Váez, Roma, D738; ver Decorme, "Menologio de varones ilustres", ms, 1940, p. 49.

12 Ibid. Ver Alegre, Historia, 1:409-10, y nota 31 abajo.

13 Breviores Commentarii... El rey (A10/el rey) dice "...por el año de seyscientos y seys auiades compuesto e impresso en la ciudad de Valencia dos libros intitulados: Breuiores Commentarij in uniuersam Aristoteles [sic] Logicam; y el otro: Breuiores Commentarij in octo libros Physicorum Aristotelis..." El provincial de los jesuitas (A10/approbatio-ego) dice que los "más breves" fueron "impresos por primera vez en Valencia en el año de 1606". En una censura de 1610 (A10/approbatio-iussa) se refiere a los Comentarios "con las añadiduras más breves insertadas en sus lugares". 
ción de Colonia, de 1605.1\$ La lógica de Rubio fue publicada al menos 18 veces en ocho ciudades europeas, y siete ediciones llevan el título de "la lógica mexịcana"."15

La lógica es la primera parte de un proyecto más amplio, el cual in. cluye obras sobre la filosofía natural $\mathrm{y}$, al menos en las intenciones de Rubio, la metafísica. ${ }^{16}$ Este proyecto, de extraordinaria ambición, sobre el trío de lógica, filosofía natural y metafísica, constituye un "curso filosófico", género literario propio de la filosofía escolástica del siglo Xvir. ${ }^{17}$

Rubio trabajaba dentro de la brillante filosofía del siglo de oro desarrollada en la península ibérica y en sus dependencias americanas. La corriente lógica se había originado en la universidad de París hacia fines del siglo $\mathrm{xv}$, cuando un grupo de profesores españoles volvieron a las universidades de Alcalá y Salamanca, iniciando así una tradición que iba a durar más de dos siglos.

\section{La Garrera de Rubio en México}

Rubio fue enviado a México, "sin haberlo pedido", especialmente para enseñar filosofía (y teología). ${ }^{18}$ Después de cinco años en América, pre-

14 Wilhelm Risse, Bibliographia Logica: Derzeichnis der Druckschriften zur Logik mit Angabe ihrer Fundorte (Hildesheim: 1965), t. I y Die Logik der Neuzeit, 399, nota 609. Hay copias de la edición de Colonia en al menos seis bibliotecas de Alemania, y una en el museo británico de Londres y una en la biblioteca nacional de París. Dos ediciones (Lyón, 1611 y Paŕs, 1615) dan "la lógica mexicana... es decir, los comentarios más breves..."

15 Las 18 ediciones registradas por Risse: Alcalá (3 ediciones), Colonia (5), Valencia (2), Cracovia (1), Lyón (4), París (1), Brujas (1), y Londres (1).

16 Rubio dice en su prefacio (A03/auctoris) que además de la lógica "tengo los comentarios que faltan totalmente preparados para completar el curso entero, es decir, los 8 libros de la Fisica, los dos Sobre la generación y corrupción, los tres Sobre el alma, con la Metafísica. Agrega que los publicará "sin demora". Salió su comentario a la Fisica por primera vez en 1605 (y el compendio en 1610), Sobre la generación y corrupción en 1619, Sobre el alma en 1611, y Sobre el cielo y mundo en 1617; véase W. Redmond, Bibliography of the Philosophy in the Iberian Colonies of America (La Haya; 1972). Rubio parece preferir la expresión "lógica y filosofía natural" - omitiendo "metafísica" (compárese la frase de arriba) _ a "filosofía" en su discusión de la relación entre filosofía y teologia (O03/auctoris). Es posible que fuese demasiada la competencia con las Disputaciones metafisicas de Francisco Suárez que aparecieron en 1597. En su introducción a la edición más breve ( $\mathrm{Al} 0=\mathrm{Cl} /$ /florentissimae), promete que "perseguir[á] todo lo que falta con igual y (si fuera posible) mayor diligencia" y asegura a los estudiantes (A10 $=\mathrm{CI} 5 /$ ad liberalium): "habeis de recibir en adelante todo lo demás".

17 Rubio usa el título más tradicional "comentarios" para su obra, pero él y otros (p. ej., el general, carta a Váez, Roma, 11 de marzo de 1602) se refieren a ella con la expresión "curso".

18 Decorme, "Menologio", ms, 1940, p. 49, D740. Carta Mercurián-Sánchez, Roma, 31 de marzo de 1576, párr. 7 y 16, D727-8. 
guntó discretamente sobre la posibilidad de volver a Europa. En 1582 escribió a un amigo, entonces asistente del general en Roma, rogándole que tratase su vuelta a España con el general, el p. Claudio Aquaviva. porque creía que podría servir mejor allá "con las letras" y "satisfacer a lo que se [le] ofrecía. ${ }^{19} \mathrm{EI}$ asistente informó a Rubio en 1584 que Aquaviva había negado su petición. ${ }^{20}$ En una carta del 25 de octubre Rubio dijo a su general que aceptaba su decisión y le explicó las circunstancias de su petición. ${ }^{21}$

Estos eventos parecen estar ligados a otro problema que tenía Rubio por el mismo tiempo: la postergación de su profesión religiosa. En 1583 Aquaviva sugirió al p. Mendoza, provincial de Rubio en México, que difiriera su profesión y que le advirtiera que se ejercitara en ciertas virtudes y que tuviera más deseos de ayudar a los indios. ${ }^{22} \mathrm{El}$ año siguiente, Mendoza respondió al general que no tenía que reprenderlo, porque lo encontró "otro" y "mejorado en todo". ${ }^{23}$ Rubio mismo ofreció otra versión en una apología que incluyó en su carta a Aquaviva en octubre de 1584: era totalmente inocente, dijo, de la acusación de no tener "afición al trato de la lengua [indígena] antes aversión al trato de ella". Antes bien, cuando era procurador de la casa en Tepotzotlán, dijo, tenía un amor especial a los estudiantes de la lengua; su mismo trabajo intelectual, en efecto, le era más significativo en México que en Europa porque

19 Carta perdida, "por marzo" de 1582; ver D742 y nota 21 abajo.

20 Carta perdida, marzo de 1584; ver D746-7.

21 Rubio-Aquaviva, México, D742-6, párr. 3-4:

...Escribí al P. García de Alarcón, asistente, ...p para que si le pareciese conveniente, tratase con V. P. de mi vuelta a España, siendo así que se juzgase poder yo allá, con las letras que nuestro señor me ha dado en la compañia, servir más a nuestro señor y a ella, por medio de la ocupación que la obediencia allá me diese. Esto propuse no como quien pretendra inquietar sus superiores con importunidad, sino propuesto abrazar con toda voluntad lo que se me ordenase, ni tampoco como quien está inquieto, que por la divina gracia ocho años ha con quietud y contento, por haber sido enviado de la santa obediencia, sino por satisfacer a lo que se me ofrecia y entender más lo que nuestro señor quiere de mí. En esta flota recibí una del p. Garcia de Alarcón en que me respondía haberlo propuesto a $V$. P. y ser su voluntad... que me esté quedo en esta tierra, como estoy. Yo me he consolado con esta respuesta $y$ digo a V. P. que estoy muy contento... y el haberlo propuesto, bien puede V. $P$. estar seguro que ha sido secreto y sin daño a nadie.

22 Aquaviva-Mendoza, Roma, 5 de diciembre de 1582, D732: “También se podrá diferir el p. Antonio Rubio, al cual avise V. R. seriamente a que tenga y muestre mayor amor a la pobreza y desprecio de sí mismo, mayor sencillez y mortificación, y deseo de ayudar a los indios. Dése más a la oración y devoción."

23 Mendoza-Aquaviva, México, 27 de octubre de 1584, D732: "...le hallo tan otro del que yo entendía, en lo que toca a la pobreza, simplicidad, afición a los indios, etc., que, gracias a Dios no he hallado que reprender; y asi me lo ha dicho el p. Juan de la Plaza, que está mejorado en todo." 
podía servir así a los indios. ${ }^{24}$ Creía que su delator, por olvido, debió de cambiar su nombre por otro, y pidió al general que le avisara en seguida si "alguna cosa llegare a Roma de mis faltas". Aquaviva dio licencia en 1586 y al año siguiente Rubio hizo su profesión. ${ }^{25}$ En 1596 oímos que ya confiesa en la lengua mexicana. ${ }^{28}$

Rubio, pues, tenía una gran confianza - la cual iba a ser justificada - en su vocación intelectual y deseaba trabajar allí donde le parecía que mejor podría realizarla. Es posible que ya en aquel entonces tuviera alguna idea del proyecto filosófico que iba a llevar a cabo después. Es comprensible que su afán por las "letras" pudiera aparecer no del todo acorde con el entusiasmado apostolado de los jesuitas hacia los indígenas (no vaciló en exhortar al general, en la misma carta que contiene su apología, a que no redujera la actividad docente de la compañía en México).

Seis años más tarde, todo estaba ya arreglado, y Rubio sabía exactamente lo que quería hacer. En 1593 la provincia mexicana solicitó el doctorado para Rubio y pidió permiso al general para que Rubio pudiera preparar un "verdadero comento" a santo Tomás, y que la obra, de ser aprobada, se publicara. ${ }^{27}$ Aquaviva concedió el permiso el mismo año, ${ }^{28}$ y cuatro años más tarde el general mencionó al provincial mexicano, F. Váez, que había oído que Rubio ya tenía "en buenos términos su

24 Párr. 10-14; 11: "Y esto puedo decir con verdad, que lo poco que trabajo en leer lo que leo y en el cuidado de los estudios, lo hago con mucho más consuelo en esta tierra por servir con ello al ministerio de la lengua y naturales, que si en España lo hiciera o en Roma, donde no pudiera inmediatamente tener este efecto."

25 Carta Aquaviva-Mendoza, Roma, 24 de febrero de 1586, Monumenta mexicana 3:150. Se profesó el 4 de enero de 1587; $i$ bid., 3:633.

${ }^{26}$ Ms del Archivo Romano SJ, 4:93-4, D734: "En el colegio de Tepotzotlán, el p. Antonio Rubio ha comenzado a deprender la lengua mexicana y confiesa ya en ella."

27 Memorial presentado al general en octubre de 1593, D734:

El sobredicho p. Antonio Rubio ha leído muchos años philosophia y teologfa con gran aceptación y saisfacción; 'desea hazer un comentario' sobre las partes del sancto Tomás que no sea questionario sino verdadero comento que declare el sentido de sancto Tomás y en el cual se defiendan y apoyen todas sus opiniones, sacándolas de sus primeras rayces y fundamentos, y se concuerden diversos lugares suyos; lo que con ser conforme a lo que se dize, sería también útil para más ilustrar la doctrina de sancto Thomás y ayudar a los nuestros que sepan cómo se ha de seguir y defender esta opinión. V. R. se contente dar esta licencia y remitirla, que acá la vean los padres Plaza, Pedro Sánchez, Pedro de Hortigosa, Loysa, o de los que destos paresciere, y aprobado, se imprima.

28 Ibid. "Se concede licencia que aquí se pide y se çomete al provincial que señale tres personas, quales más convenientes le pareciere para que vean y examinen lo que el p. Rubio escriviere en la manera que aquí se pide." Carta Aquaviva-Díaz, Roma, 9 de mayo de 1594, D734: "siento que le falte la salud, porque según me han informado es un sujeto apto para las letras, pero bien ocupado estará en escribir". 
curso de artes" y quería que de ser aprobado, se imprimiese en España. ${ }^{2 \theta}$

En 1599, la provincia facilitó la travesía a Europa para Rubio eligiéndolo procurador. Aquaviva informó a Váez en 1602 que Rubio había desempeñado su misión fielmente, y que iba a quedarse en España, no sólo para publicar su curso, sino también porque allá podría emplear mejor su talento. ${ }^{30}$ Como consuelo, prometió que mandaría a México en trueque de Rubio "sujetos de importancia"."31 El mismo año de 1602 fue a España; el año anterior la corte española había dado licencia de imprimir la lógica y un año después salió la primera edición..$^{32}$

\section{LOS MATERIALES PREPARATORIOS}

Los impresos de filosofía (y de otros temas) en el tiempo de Rubio solían contener escritos cortos puestos entre la portada y el texto prin-

29 Roma, 20 de junio de 1598, Archivo de la Provincia Mexicana, D747: "entiendo que el p. Rubio tiene en buenos términos su curso de artes; $V$. $R$. le ha ver a algunos de esos padres más provectos y aptos, $y$, siendo tal, cosa que yo espero que será, es bien que le imprima, y esto será mejor en España que por allá".

30 Roma, 11 de marzo de 1602, D738:

El p. Antonio Rubio ha hecho el oficio que V. R. y essa provincia la encargaron con tanta solicitud y fidelidad como en sus despachos verá, y pues $\mathbf{V}$. $R$. en su carta nos dice que una de las causas porque le eligieron fue porque con la ocasión de su venida imprimiese su curso, essa misma en parte hemos tenido acá para que él se quede en España, pues de otra manera no le podrá imprimir; pero la principal es porque servirá más por acá que por allá, pues conforme a lo que $V$. $R$. ha escrito, ni él ha de gobernar allá ni ha de leer ni exercitar sus letras, por las razones que V. $R$. me ha apuntado. $Y$ en España podrá ayudar con su talento en letras, especialmente siendo como dicen que es, tan aficionado a sancto Thomás y seguidor de su doctrina, que para los tiempos que corren es una parte importantísima. En trueque de él le enviamos el provincial p. Ildefonso Castro de España y otros sujetos de importancia.

31 Ver nota anterior. La provincia mexicana sintió la pérdida de Rubio, cuyos informes y "dichosa venida" se guardaban en 1602 (D736, 747). Después de enterarse de que Rubio iba a quedarse en Europa, la provincia pidió al general en su sexta congregación, celebrada en 1603, que "sabiéndose estar ya la puerta cerrada [de volver los procuradores a América], se quite la ocasión de lo contrario y se estorven los muchos daños que de ello se seguirian", los cuales eran el incumplimiento de la costumbre de dar cuenta personalmente de su misión y el debilitamiento del compromiso de "dejarlo todo" para ir a América (Actas, D737). Es interesante que Aquaviva rehusó permiso más tarde para que otro padre que trabajaba en México imprimiese su curso - más corto que el de Rubio-, porque, dijo el general, Rubio ya había publicado un "epitome" y "por no multiplicar tantos por ser tan pocos los padres que en essa provincia hay, que será [el padre] bien menester para otros em. pleos y occupaciones", carta Aquaviva-Peláez, Roma, 15 de septiembre de 1609, D748-9.

32 Ver la carta Aquaviva.Váez, Roma, 15 de abril de 1602. A03/el rey, Valladolid, 18 de marzo de 1601; Felipe III se dirige a Rubio: "Vos auiades compuesto unos Comentarios sobre toda la Logica de Aristoteles, lo qual era muy util y os auia costado mucho trabajo." Risse (comunicación personal, 28 de abril de 1981). 
cipal. Podían estar en latín o en la lengua vernácula y eran de varias clases: permisos para imprimir o vender la obra, "censuras" como los imprimatur actuales pero que generalmente hacían propaganda del libro, poesías en alabanza del autor, prefacios y dedicatorias del escritor, etc. A veces tienen gran interés histórico por dar informes importantes sobre la intención del autor, las circunstancias de la publicación, etc. ${ }^{33}$

Hemos examinado 21 (6 se repiten en más de una edición) textos prefatorios de la lógica de Rubio. Son clasificables en varios géneros. Hay listas de erratas (2), tasas (2), declaraciones de corrección religiosa y permisos de publicación y venta (10), una advertencia sobre la impresión de obras de jesuitas (1), y una carta del autor en que dedica la primera edición al obispo de Málaga, exprofesor de la Universidad de Alcalá. Más importantes son tres escritos en latín por Rubio:

- A03/auctoris: el prefacio al lector en la primera edición en que Rubio explica sus motivos al concebir su proyecto filosófico, explica su estructura y formato, etc.

- Al0=C15/florentissimae: carta a los profesores de la Universidad de Alcalá a modo de prefacio (y dedicatoria a los mismos maestros) de la edición más breve, en la que les agradece por aceptar su lógica como texto oficial de la Universidad, explica el origen del compendio, etc.

- A10=C15/ad liberalium: prefacio a los estudiantes en la edición más breve en que Rubio explica sus motivos de redactar el compendio

(la traducción de estos tres escritos se halla en el apéndice) y dos textos en español relativos al uso de la lógica de Rubio como texto oficial de la universidad de Alcalá:

- A03/testimonio: una constancia por Luis de la Serna, secretario de la universidad de Alcalá, de un decreto hecho por el claustro de profesores y confirmado por el rey que manda "recibir esta Logica del Padre Doctor Antonio Rubio... por Autor proprio de la mesma Uniuersidad, y a los Cathedraticos de Artes que como tal la lean en las Aulas a sus Estudiantes".

-A10/provision: provisión real "por la qual su Magestad confir-

33 P. ej., un análisis de tales textos en libros de filosofia (y teologia) del virreinato del Perú en el siglo xvir revela una sorprendente autoconciencia (y defensa) de la intelectualidad americana frente a Europa. Ver "Una defensa de la América intelectual: Apologías por pensadores coloniales del siglo xvi", Latinoamérica (UNAM), n. 14, 1981, y "La defensa de la América intelectual: documentos coloniales", Fénix (Biblioteca Nacional del Perú), n. 26, 1979. 
ma el decreto de la Vniuersidad de Alcala, y manda se guarde", con dos notas agregadas.

\section{Motivos de la publicación de los Comentarios}

Rubio mismo dice que la intención principal que motivó la concepción de su proyecto filosófico fue pedagógica: el provecho de los estudiantes. ${ }^{34}$ Pero para cumplir con su propósito tenía una serie de ideas que corresponden a críticas especificas del sistema universitario de entonces, fruto de su larga "experiencia" (A03/auctoris) en la educación. Repasamos algunas de sus innovaciones, todas explicadas en más o menos detalle en su primer prefacio al lector.

Introduce el tema de las razones que tenía para realizar su proyecto contándonos de la sorpresa que causó el anuncio del mismo. En su día la filosofía, además de ser una materia estudiada por sí misma, era un requisito previo en el programa de estudios para otras materias como teología y derecho. Naturalmente, la mayoría de los estudiantes tenían más interés en estas carreras que en la filosofía. Rubio nos dice en efecto que loś que "adelantaban" la lógica: eran supuestamente "en general los que tienen más ardor de juventud y más entusiasmo en los estudios recientes" (A03/auctoris). La palabra "recientes" parece aludir a la actividad en la lógica a través del siglo xvi en Iberia y América.

Ahora bien, Rubio dice que después de llegar a México, enseñar filosofía y teología, ganar cuatro títulos, y servir a la educación por 25 años, "volvi[ó] a ser niño" y regresó al estudio de la filosofía. Se asombraron sus colegas y estudiantes y preguntándose por qué un hombre -ya no joven (frisaba en los 45 años) - que había tenido tanto éxito en el cumplimiento de quehaceres más importantes, "quisiera envejecerse" en la filosofía. En su prefacio Rubio expone las razones de su decisión tan asombrosa.

\section{Madurez}

Su primera crítica —es evidente - se relaciona con la estructura de la educación. Si la mayoría de los que hacen filosofía son jóvenes, con-

34 Rubio quiere que se juzgue su lógica por este criterio: si a los estudiantes les "ayuda a iniciarse en las artes liberales, evitando así que se desanimen por la magnitud de la materia con el resultado de que se desesperan de dominar la materia y abandonan su carrera" (A10=C15/florentissimae; ver también A03/auctoris, Al0=Cl5/ad liberalium). El rey notó que el uso de la lógica de Rubio sería "conveniente al aprovechamiento de los estudiantes" y su rechazo conduciria a su "notable daño y detrimento". También Al0/approbatio-iussu y C15=L19/iussu. 
viene que también trabajen en ella los que tienen más experiencia intelectual. Rubio afirma que si bien "muchos" han abordado proyectos parecidos en la filosofía y con alabanza, no lo han hecho "tantos con la madurez y experiencia de que haría falta". Pero cuando dice "experiencia", se refiere de manera especial a la teologia.

\section{Filosofia y teologia}

Otra crítica, en efecto, es que la enseñanza de la filosofía no está adaptada a la teología. Pues los estudiantes tienen que aprender, dice, muchas "cuestiones sutiles" en la filosofía, las cuales tenían que "desaprender" después, por tener poca importancia para sus estudios posteriores, sobre todo la teología. Además, si bien la teologia que se impartía en las universidades del mundo católico era tomista, la filosofía no gozaba de tal uniformidad, y Rubio se propone escribir una filosofía aristotélicotomista, la cual, por su correspondencia a la teología, remedie esta deficiencia.

Estas observaciones de Rubio son muy compatibles con ciertos desarrollos de la historia de la lógica del siglo de oro. A mediados del siglo xvi se llevó a cabo una reforma en la enseñanza de la lógica ( $y$ en la filosofía generalmente), en reacción contra un florecimiento, en la primera parte del siglo, de la lógica "nominalista" que venía de París. Los reformadores, bajo influjo humanista y con propósitos pedagógicos, querían reducir el contenido de la lógica impartida en las universidades, especialmente lo especifficamente escolástico, y agregar más doctrina aristotélica, preparándose, p. ej., más comentarios a los Tópicos..$^{35}$ Al mismo tiempo se aumentó la fuerza del tomismo en la segunda mitad del siglo xvi, y el deseo de Rubio de acomodar la filosofía a la teología tomista parece corresponder a esta tendencia. Sin embargo, es interesante que Rubio se niegue a comentar los Tópicos y Primeros Analíticos. Ofrece una buena razón de omitir la segunda obra, pues, dice, su materia se ha incorporado a las súmulas, o primera parte del curso dedicada a la lógica formal. Pero es más ambigua su razón de omitir los Tópicos, pues cree que sólo pertenecen al estudio de la retórica (A03/auctoris). ${ }^{36}$

3 Véase resumen en W. Redmond "Formal Logic in New Spain: The Work of Fray Alonso", International Philosophical Quarterly, t. 19 (septiembre de 1979), 331ss; "La lógica formal en la Nueva España: Aspectos de la obra de Fray Alonso", Latinoamérica, n. 12, 1979, 225ss. Véase también Vicente Muñoz Delgado, Lógica hispanoportuguesa hasta 1600: notas bibliogrdficas (Salamanca, 1972). Claro que "simplificación de la materia" no significa "materia simple".

36 La actitud de Rubio de recortar la filosofía para ajustarse bien a la teología parece confirmar la crítica frecuente contra la filosofía escolástica de que ésta sea la sirvienta (ancilla) de la teología. En efecto, Rubio dice en este pasaje que la lógica y la filosofía natural "sirven" a la teología ("ancillari tamquam illi [theologiae] 


\section{El dictado}

No obstante, el motivo especial de Rubio al concebir su proyecto de un curso filosófico nuevo fue, según la expresión real, evitar "que se escriua en las aulas". ${ }^{37}$ Rubio piensa que el peor enemigo de la educación, el fastidio más grande en la sala de clase, pérdida de tiempo e insulto a la inteligencia de los buenos estudiantes, es la costumbre que ve casi universal del "dictado": el profesor diota el resultado de sus propios estudios a los estudiantes y éstos lo tienen que apuntar. Atribuye este mal a la ambición de los profesores ("quieren mandar sus ocurrencias por escrito a sus alumnos y a la posteridad") o a la flojera de los estudiantes ("juzgan importante captar y memorizar lo que el profesor discute en la clase"- A03/auctoris). Los antiguos, cree, eran mejores filósofos porque no tenían que apuntar las conferencias de sus maestros. En resumidas cuentas, dice, los alumnos "tienen sus conocimientos en sus códices" y salen de filosofía más secretarios que filósofos. ${ }^{38} \mathrm{El}$ propósito de Rubio es publicar un "almacén" [promtuarium] de toda la filosofía, antigua y moderna, tan completo y hábilmente construido que contendría todo lo necesario para el estudiante. La ventaja de su curso, dice, fuera de eliminar la necesidad de manejar muchos libros, es que acabaría con el dictado.

Rubio hace propaganda de su curso en su prefacio. El profesor que use sus libros como su texto único para toda la filosofía, dice, tendrá las clases más animadas y los estudiantes ya no bostezarán. Éstos, en efecto, como los filósofos de antaño, prestarán atención a las discusiones en clase y las seguirán discutiendo después entre sí. La razón es que no tendrán que copiar nada ni estar "cortando sus plumas ni puliendo su

familiares esse"). Pero hay que comprender las razones que da para defender su plan. Existe una relación tan estrecha entre la lógica y física por un lado y la teologia por otro, dice, que un error pequeño en aquéllas acarreará errores más serios en ésta. Pero su razón es que la teología presupone la filosofía como base, sin investigar ella misma los temas fundamentales de la lógica ni de la filosofía natural ("hisce fundamentis niti debeat"). Si la base no es maciza, dice, se desplomará la teología. Rubio, pues, implica algún influjo de la teologia en la filosofía -en general, evitar discrepancias y coordinar su materia-, pero su punto es más bien lo contrario: la lógica y la filosofía natural deben desarrollarse seriamente y con sofisticación porque constituyen una fuente esencial para la teología. La dependencia está al revés en el sentido de que la teología, si bien tal vez no es la ancilla de la filosofía, ha sido - y sigue siendo- altamente derivativa de ella y de otros aspectos del complejo intelectual. Pero hay que precaverse de una actitud a priori en esto; para establecer el influjo de la teología en la lógica, habría que señalar explícitamente las supuestas alteraciones, omisiones, etc. Pero lo importante aquí para Rubio es que si filosofía y teologia han de ponerse de acuerdo, hay que compararlas cabalmentey ¿quién puede llevar esta tarea a cabo sino alguien que haya estudiado la teologia? 37 Al0/prouision y la segunda añadidura. Rubio desarrolla esto en A03/auctoris.

38 "...codicibus onusti totam fere scientiam in ccriptis habent,... graphici et liberales notarii potius euadant quam perfecti atque absoluti dialectici et philosophi." 
papel". Pero ¿ji el profesor no está de acuerdo con las ideas de Rubio? Bueno, en primer lugar, dice, "si es verdadero discípulo de Aristóteles y santo Tomás" discrepará muy pocas veces, y en segundo lugar, siempre podrá refutar a Rubio y "tratar de probar" [adstruere] su propio parecer- sin que los alumnos tengan que apuntar. ${ }^{39}$

\section{LA CONTROVERSIA}

Lo que sugierè Rubio, entonces, es que todos los profesores de filosofía utilicen solamente sus libros en sus clases- o sea que quiere que su curso sea el texto oficial de la Universidad de Alcalá. Si este propósito nos parece presumido, pues reduciría notablemente la libertad y creatividad de los profesores, y muestra una confianza extraordinaria en su propia capacidad filosofica, hay que recordar que el claustro de profesores de la Universidad de Alcalá efectivamente accedió a sus deseos. Emitieron un decreto, el cual fue confirmado también por el rey, en que declararon a Rubio autor oficial de la Universidad en la filosofía e hicieron su curso el texto oficial, obligando a todos los profesores. a usarlo en la clase. No debe causar sorpresa, sin embargo, que hubo un "malentendido" y "excusas" (C10/provision), si no una rebelión, de los profesores afectados, y fue el rey mismo quien tuvo que poner el decreto del claustro en vigor y obligar con amenazas a los profesores a "leer" a Rubio en sus clases.

\section{El decreto}

El testimonio del decreto (A03=C15/testimonio), fechado el 28 de febrero de 1604, hace los siguientes puntos. La lógica de Rubio había sido examinada por siete profesores designados de la Universidad de Alcalá de teología, medicina y filosofía. Presentaron un informe en el claustro de profesores afirmando que la obra era "muy conforme" no sólo a la interpretación complutense de la doctrina de Aristóteles y Aquino, sino también "al modo que se ha tenido de leer Artes en esta Vniuersidad" y que el autor "disputa" las cuestiones "con mucha agudeza, erudición, claridad, y buena disposición". El claustro, entonces, decretó por unanimidad que la lógica de Rubio "se recibiese en esta

39 El formato que describe Rubio en A03/auctoris está acorde con los propósitos generales de su obra: presenta el texto de Aristóteles en la traducción de Boecio con aclaración y observaciones sobre puntos dificiles o de importancia especial, y entonces "llama en controversia toda la doctrina de Aristóteles". Sugiere al profesor que disponga la materia de sus clases para no sobrecargar a sus alumnos. 
Vniuersidad por Autor proprio y como tal se leyesse y esplicase por los Cathedraticos de Artes en las Aulas".

El rey dio licencia y confirmó este decreto por una provisión real en que obligaba al lector de la Universidad a ejecutar el decreto y proveyó un auto ante Serna, secretario de la Universidad, "por el qual mando a los Cathedraticos de Artes, que leyessen la Logica por el dicho libro, teniendole por vnico Autor, y proprio de la uniuersidad, con ciertas penas contra el que no lo cumpliesse". Y Serna a su vez el 28 de febrero de 1604 "estando leyendo los Cathedraticos a sus dicipulos en las Aulas les notifi[có] el dicho Auto, ansi a los Cathedraticos de Logica como a los demas Cathedraticos de Artes de esta Vniuersidad", y firmó y selló el documento "para que se pusiesse en el principio del dicho libro".

Rubio, desde luego, estaba muy agradecido a sus colegas alcalaínos y al dedicarles sus Comentarios más breves dijo ( $\mathrm{Al0}=\mathrm{C} 15 /$ florentissimae) que porque habían mandado que los maestros "explicaran los Comentarios a sus discípulos", estaba "tan obligado por un vínculo de estrecha amistad y amor,... que no había nada útil ni grato para la Universidad que no debiera emprender e intentar".

\section{La provisión del rey}

El rey mandó una carta (A10/provision) al rector de la Universidad el 29 de octubre de 1605 para ocuparse del incumplimiento del decreto original. Había sido informado indirectamente por Pedro González Corral, visitador de la universidad, sobre los problemas. González le recordó que la universidad le había pedido el año anterior (1604) que confirmara el acuerdo que hizo que Rubio fuera el autor oficial, "cuya execucion era muy conueniente al aprouechamiento de los Estudiantes de [filosofía] por las razones que en el dicho estatuto y acuerdo se auian representado..." Pero la "carta e prouision" del rey en respuesta a esta petición, dice el visitador, no se cumplió enterameñte, pues "algunos de los dichos Cathedraticos, entendiendo mal la dicha... carta e prouision [del rey]; respondian que preceisamente no se les mandaua que guardassen el dicho estatuto y acuerdo, sino se les dexaua en su facultad, interpretando en esta conformidad, la licencia que se daua por la dicha nuestra carta e prouision: y assi no queriendola obedecer en todo, auian dexado de leer por el dicho libro, en notable daño y detrimento de los dichos Estudiantes, y auia dexado de executarlo, por ser los dichos Cathedraticos, o la mayor parte dellos de su Colegio".

González Corral descubrió el incumplimiento y proveyó auto del 3 de febrero de 1605, mandando que se cumpliera la "carta e prouision con- 
firmando el dicho estatuto y acuerdo, para que se guardasse con las penas en el contenidas, poniendo otras de nuevo". Y encargó al rector y al visitador $y$ a sus sucesores de la ejecución de la orden.

\section{La edición breve}

Entre tanto surgió otro problema. Después de alguna experiencia con la lógica de Rubio, tanto profesores como estudiantes descubrieron que era más larga de lo "que pedía la antigua costumbre de la Universidad" $(\mathrm{A} 10=\mathrm{C} 15 /$ florentissimae). $\mathrm{Y}$ porque los "hombres muy graves y doctos" creyeron "grato y útil" que Rubio volviera a publicar la obra en forma "más breve", detuvo sus otras actividades y preparó el compendio, "no sin el aplauso de los muchos que lo habían deseado ardientemente hacía tiempo", pues los estudiantes insistían en una simplificación de la simplificación. ${ }^{40}$

\section{REFLEXIóN}

Las últimas ediciones de la filosofía de Rubio fueron impresas antes de 1650; es decir, la boga filosófica de Rubio, a todas luces, coincide con la primera mitad del siglo xvir. En esta nota hemos considerado algunas razones "externas" del origen de su lógica y de su éxito, es decir, las esperanzas que abrigaba Rubio para sus escritos filosóficos y cómo se cumplieron, aparentemente, estas esperanzas, pese a las inevitables dificultades.

Sin embargo lo más significativo de la labor intelectual de Rubio y el criterio real de cualquier éxito que hubiera tenido, es su contenido filosófico. La explicación real de su triunfo se encuentra en su filosofía misma: la credibilidad de sus tesis filosóficas y la fuerza de los argumentos que propuso para establecerlas - no tanto los problemas del "dictado", de la relación entre el programa de filosofía y el de teología, de la inmadurez de la actividad filosófica, o la necesidad de una simplificación de la materia de la lógica. La elección de Rubio como autor propio y de sus libros como textos oficiales de la universidad de Alcalá - y el hecho de las numerosas ediciones de éstos- fue a base de su excelencia filosófica. $O$ sea que la razón de su éxito es, en un sentido importante, interna a la filosofía.

$40 \mathrm{~A} 10=\mathrm{C} 15 /$ florentissimae. Rubio dice a sus estudiantes en los Comentarios más breves, jugando con las palabras "petistis/expetistis": "brindamos lo que hace tiempo habéis pedido, aun más, apetecido". También el obispo de Valencia, Juan de Ribera, menciona en su censura de la misma edición (Cl5 $=$ L19/iussu) que fue por los ruegos de los estudiantes de Alcalá que reeditó la lógica en forma compendiada. 
Finalmente, notemos que Rubio trabajaba en una tradición lógica altamente exigente; su éxito no es el de una rana grande en una charca pequeña. El marco general de la filosofía en que trabajó es la sofisticada filosofía del siglo de oro. Ahora bien, en aquel tiempo la mejor lógica se realizaba dentro de la corriente escolástica, con algunas excepciones como Leibniz. ${ }^{41} \mathrm{Y}$ dentro de la escolástica misma, el trabajo que se hacía en la tradición ibérica (e iberoamericana) era mucho más interesante que el que había al norte de los Pirineos. ${ }^{22}$ Y la filosofía de que formó parte Rubio está siendo justipreciada hoy en día dentro de corrientes filosóficas actuales que muestran el mismo interés por la lógica que tenía la escolástica del pasado.

\section{ApÉNDICE I}

\section{Una cronologia}

- 1576: Rubio va a México a los 28 años

- 1577: comienza a enseñar la filosofla

- por 1580: comienza a enseñar teologia

- 1582: pregunta sobre la posibilidad de volver a Europa

- 1583: el general difiere su profesión

- 1584: el general rechaza su petición de volver a Europa - reivindicación de Rubio

- 1587: hace profesión

- por 1592: deja de enseñar la teología

- 1593: la provincia mexicana pide permiso al general para que Rubio prepare su curso

- el general otorga el permiso

- (para octubre) ya está trabajando

- 1594: recibe doctorados en filosofía y teologia

- 1598: el general dice que el curso está "en buenos términos"

- 1599: electo procurador

- principios de 1600: va a Roma

- 1601: la corona española da licencia para imprimir y vender la lógica

- 1602: terminada su misión de procurador, va a España - el general explica por qué Rubio se queda en Europa

- 1603: tasas y censuras de la lógica

41 Pero Leibniz mismo dependía de la escolástica; véase H. Burkhardt, Legik und Semiotik in der Philosophie von Leibniz (Munich: 1980), donde se describe como "Jano", con un rostro vuelto hacia el pasado y otro hacia el futuro.

42 Risse, Die Logik der Neuzeit, p. 410. 
- siete maestros de Alcalá examinan la obra e informan al claustro, el cual saca un decreto haciendo a Rubio "autor propio" y su obra oficial y obligando a los maestros a usarla en la clase

- 1604: la universidad pide al rey confirmación de la decisión

- "carta e prouision" del rey confirmando el decreto del claustro

- Serna, secretario de la universidad, notifica a los interesados y redacta un testimonio del decreto

- no se cumple el decreto, hay "malentendidos" y "excusas"

- 1605 (febrero): González Corral, visitador de la universidad, descubre el incumplimiento, prové un auto mandando cumplimiento de la carta del rey, informa al rey pidiendo otra "carta e prouision" para confirmar otra vez el acuerdo original

- (octubre): "carta e prouision" del rey dirigida al rector y visitador (y a sus sucesores) confirmando el acuerdo

- 1606: primera edición de los Comentarios más breves.

\section{ApÉNDice II}

Ofrecemos una traducción de los tres documentos escritos en latín por Rubio, tomados de los materiales prefatorios de su lógica.

\section{A03/auctoris}

PREFACIO DEL AUTOR AL LECTOR

Después de enseñar la filosofía de Aristóteles en el programa de tres años y la sagrada teología por doce años continuos, después de obtener los grados de magisterio y del doctorado en ambas áreas de la muy floreciente Universidad real de México, y después de trabajar con todo mi empeño para servir y en algo adelantar las letras [rem literariam] durante 25 años (pues hace casi tanto tiempo desde cuando fui llevado a estas costas mexicanas como estudiante de la Universidad de Alcalá por mando de Dios mediante mis superiores sus siervos), se me ocurrió el proyecto de volverme niño por así decirlo y volver a ocuparme de las materias que ordinariamente son la iniciación [auspicium] y aprendizaje de las demás en que tanto me había ejercitado con descomún asistencia de estudiantes y con fruto de que no tengo que arrepentirme (con la buena ayuda de Dios), hasta tal punto que hasta mis discípulos y mis amigos mismos (quienes habian observado constantemente mi habi- 
lidad cualquiera que sea y mi diuturna actividad en la escuela de teologia) se extrañaron por qué un hombre de madura edad, ocupado en estudios más importantes y en otros asuntos de más utilidad al estado (tal es el respeto y la emulación de los estudiantes hacia sus maestros), repitiera los estudios filosóficos y quisiera envejecerse en ellos, como los que trabajan para adelantar y adornar estas artes son ordinariamente los que tienen más ardor de juventud y más entusiasmo por los estudios recientes.

En efecto (para confesar la verdad y explicar brevemente mi proyecto), la razón misma que podría disuadirme de estos estudios menores según el juicio de muchos fue la que me motivó y por así decirlo me impelio a aceptar la tarea - si bien muchos [plures] la han emprendido con alabanza, no tantos con la madurez y experiencia de que haría falta-, no para instruir a un filósofo mediano [mediocrem] sino para formar a un teólogo acabado y perfecto. Pues ¿quién no sabe que entre todas las artes llamadas liberales y nobles son sobre todo la lógica y las disciplinas filosóficas las que sirven a la divina teología, le son como sirvientas, o (si se permite hablar así) le están ligadas por tan estrecho vínculo de afinidad e intimidad que quien yerra en puntos de lógica o filosofía natural no puede sin error absorber la sabiduría en torno a Dios. Antes bien, quien yerra ligeramente en estas materias que preparan el camino a la teologia se equivocará más seria y torpemente en la sacra doctrina misma, puesto que ésta ni enseña ni investiga los principios y las tesis de la lógica y de la ciencia natural, sino que los presupone para proceder a cosas más elevadas y difíciles. Pero si el edificio tan enorme de la divina teologia, construcción tan espléndida, ha de descansar sobre estos cimientos, éstos iqué firmes y macizos deben ser! O si no lo son ¿qué ruina no habrá que temer?

Yo personalmente he pensado siempre (no es una creencia frívola sino una experiencia de todos los días confirmada por las opiniones de los prudentes) que nadie sin temeridad puede dar ni un paso hacia las ciencias divinas si no se ha instruido equilibrada y juiciosamente en las humanas. Tampoco interesa tanto a los candidatos de la sagrada teología adquirir gran cantidad de puntos lógicos y filosóficos y una rica y fina colección de cuestiones sutiles, sino fijarse los pies en la verdadera y sólida filosofía de Aristóteles como propuesta entera, pura y claramente por su egregio intérprete santo Tomás —el tipo de doctrina que exige la sabiduría divinamente revelada por su verdad y además por su dignidad y distinción.

Y efectivamente si por divina providencia las universidades más florecientes del mundo donde hay piedad verdadera, mente sana, y religión pura han aceptado con ambas manos como dicen la doctrina del doctor 
angélico en el campo de la teología, la comprenden y enseñan, y la proponen a todos los estudiantes de la facultad a comprender y aprender, ¿por qué los que dedican su tiempo y trabajo a la indagación y aclaración de las sutilezas de la lógica y los secretos de la naturaleza no actúan de tal manera que lo que enseñan oralmente a sus alumnos o sacan por escrito en sus comentarios fuera tal que desembarazara el acceso a la teología y en vez de contradecirla, tras cuidadoso cotejo [summa contentione], acordara y se relacionara con ella tan estrechamente que tú absorberías de los primeros rudimentos de la lógica, sin tener que desaprenderlo, lo que quisieras retener por todo el programa de estudios?

Pero el único que podrá garantizar esto como se merece es el que compare los puntos teológicos con los filosóficos después de mucho tiempo de familiarizarse bien con la Suma Teológica de Santo Tomás. Es por eso que no será fuera de caso si repito y regreso el progreso que hice en la sagrada teología adonde hay que buscarlo con utilidad y lucro.

Hay otro motivo de nuestro proyecto que me indujo a emprender esta carga, el cual, si bien lo mènciono en último lugar, fue quizás el primero en mis deseos. Es a saber publicar comentarios a la lógica y a toda la filosofía de Aristóteles tan abundantes y completos y manejados [diggestos] con tanto cuidado y tanta precisión, que prácticamente no hay nada de doctrina sólida y de erudición verdadera y probada, ya sea extraída de las fuentes de los antiguos o acumulada por el ahínco y solicitud de los modernos que a estas nuestras lucubraciones no pueda pedirse.

La ventaja que tiene esto entre otras tanto para profesores veteranos como para discípulos principiantes es que podrían sacar de este almacén único por así decirlo las materias no sólo esenciales sino útiles por la razón que sea, sin gran costo y aparejo de libros, evitando así el tedio, con mucho el más molesto ni menos enemigo de las buenas artes, de dictar y copiar [excipiendi], de escribir y transcribir códices. Casi todos en la universidad habrán aceptado ya la introducción de esta costumbre, no sé si por la ambición de los maestros (por querer mandar sus ocurrencias por escrito a sus discípulos y a la posteridad) o bien por la apatía y pereza de los estudiantes (pues juzgan importante captar y memorizar lo que el maestro discute de viva voz). Pero (con cuánto daño a los estudios, pérdida de tiempo, y deshonor a los buenos ingenios! Por testigo pongo a la misma experiencia y a los filósofos más antiguos, quienes, porque no apuntaban nada en las academias [gymnasiis] sino que escuchaban cuidadosa y diligentemente a las discusiones de su maestro y las continuaban entre sí en frecuentes reuniones, alcanzaron un grado de erudición al cual llegan pocos hombres de esta edad. Éstos, cargados de códices, tienen casi todos sus conocimientos en sus escritos, pero no tienen ninguna consideración [tribuunt] para las clases [scholis] y 
ejercitaciones diarias, o tan poca que salen al final del programa de las artes liberales más como escribanos liberales y elegantes que lógicos y filósofos cabales y perfectos. Es por eso que nuestra Sociedad (a la que dedicamos nuestros intentos y labores de manera especial), desea y manda en la Ratio Studiorum que en los años anteriores impuso a sus profesores que [ut si] los maestros puedan, además del dictado, enseñar de tal manera que sus oyentes puedan copiar cómodamente lo que hay que apuntar, para que no dicten un discurso [verbum] sino que discurran [praelegant] de viva voz.

Ahora bien, no creo que haya ningún profesor que quiere revolver nuestros Comentarios y presentarlos claramente a sus alumnos, que no pueda recorrer toda la filosofía fácil y cómodamente sin dictar nada. Pues si alguna vez encuentra alguna opinión con que no esté satisfecho (pero si es verdadero discípulo de Aristóteles y Santo Tomás tales encontrará raras veces), podrá refutarla de viva voz e intentar probar la contraria. Pues ¿cuál estudiante será tan obtuso y torpe que no pueda sin códice captar estos pocos puntos que raramente ocurren? $\mathrm{Y}$ resultará que la fuerza de la viva voz rendirá las materias mismas más claras por ser repetidas varias veces, y las fijará más firmemente en las mentes de los oyentes, cuyo deber será despertar oído y espíritu -en vez de afilar plumas y pulir papel- para después estudiar las conferencias [praelectiones] frecuentemente - las cuales ya no oirán con bostezos-, discutirlas entre sí, y, ora defendiendo ora refutando, examinarlas, cuestionarlas, ventilarlas.

Por estas razones y otras que prefiero omitir, hemos preparado y publicado estos Comentarios de materias lógicas para la gloria de Dios óptimo y máximo y para la utilidad y provecho de los profesores y alumnos de las buenas artes. Me resta explicar en pocas palabras el procedimiento que escogido, si bien salta a la vista bastante bien incluso al mismo principio. En general será fácil y claro. Desplegamos el texto de Aristóteles por capítulo, o al menos el comienzo de cada uno, en la traducción latina de Boecio Severino (por ser más fiel a la letra, más grave y elegante, merecidamente suele preferirse a las demás), agregaremos nuestra explicación para aclarar el texto y entonces algunas notas si en alguna parte lo pide la importancia o dificultad de la materia, y finalmente llamaremos en controversia toda la doctrina misma de Aristóteles, para que su verdad se haga más lúcida y evidente, y lo haremos por cuestiones sencillas - sin artículos, secciones, ni otras divisiones que producen oscuridad para los principiantes.

Será el deber del maestro al explicar las cuestiones oralmente, disponerlas [diggerere] y distribuirlas de tal manera que sus conferencias [praelectiones] diarias no crezcan más de lo justo, para que en todo tenga 
en cuenta la capacidad y memoria de sus oyentes. Mantendremos este método por todo. Ahora bien, si para tener un tratamiento exacto y completo de las materias lógicas, alguien desea exposiciones de los libros de los Tópicos y Primeros analíticos, las buscará y procurará de otra parte. De nuestra parte consideramos supérfluo exponer los libros de los Primeros analiticos en un tratado especial, porque se habrán estudiado suficientemente cuando se presente la ocasión en la introducción de la lógica llamada "súmulas". Y los lugares tópicos ¿quién no ve que pertenecen a la consideración de la retórica? Hemos juzgado suficiente, pues, ilustrar con nuestros comentarios todos los libros de la lógica que suelen ser explicados en las escuelas, para que por consiguiente toda la lógica de Aristóteles que te entregamos sea apreciada por el mejor de los derechos.

Por otra parte, tengo totalmente preparados los demás comentarios que faltan para completar el curso entero, digo, los ocho libros de la Física, los dos Sobre la generación y corrupción, los tres Sobre el alma, con la Metafisica, y te los ofrezco a ser editados (si la vida me acompaña) sin ninguna demora.

Te resultarán más útiles ciertamente si los lees que si antes de leerlos crees que hay que rechazarlos, y menos ofenderás si al leer algo lo lees con el celo de aprender que si sólo piensas en condenarlo.

PARA LA UNIVERSIDAD DE ALCALÁ, MUY FLORECIENTE Y CÉLEBRE EN EL MUNDO ENTERO, EL PADRE DOCTOR ANTONIO RUBIO SUPLICA LA DOBLE FELICIDAD

Rector dignísimo, doctores y maestros muy graves y sabios, célebre Academia distinguida por muchos honores:

He averiguado que nuestros Comentarios a la lógica os aparecieron tan dignos que tras ser aprobados por voto y sentencia de todos en consejo, mandasteis para formación de la juventud que los profesores y maestros de la lógica se los explicasen a sus discípulos. Este decreto vuestro fue después confirmado y afianzado por la autoridad del rey por ser útil para los estudiantes poder aprender la doctrina auténtica de esta Universidad y cónsona con la enseñanza de Aristóteles, la cual, a vuestro juicio, se halla en estos Comentarios.

Por estas razones, claro está, mi espíritu entero, muy dedicado hacía tiempo no sin mérito a esta universidad, llegó a ser tan obligado por un vínculo de estrecha amistad y amor, que no creía que hubiese nada útil o al menos grato, a mi juicio, para esta universidad que no debiera emprender e intentar. 
Ahora bien, porque los hombres muy graves y doctos de esta universidad, a quienes reconozco mi obligación por muchas razones, constataron que nuestros Comentarios eran más largos que pedía la antigua costumbre de la universidad, pensaron que sería grato y útil si * volviera a publicarlos reducidos a un compendio, no sin el aplauso de los muchos que lo habian deseado ardientemente hacia tiempo. Porque, pues, continuaban animados por celo del bien común y me lo rogaron repetidas veces, habfa que obedecer del todo las peticiones de aquellos cuya autoridad, valiosa para mí, dirigió mi espíritu que ya se apresuraba a otras cosas, a aceptar la tarea en seguida. Lo acepté efectivamente y lo llevé a cabo con la diligencia que pude. Ya tenéis, hombres muy graves, este compendio: casi ya no más ${ }^{\dagger}$ nuestro sino totalmente vuestro, pequeño en efecto en tamaño pero el más grande en el deseo de complacer.

En él habría que juzgar al menos o especialmente esto: si ayuda a los ingenios a iniciarse en las artes liberales, en vez de estar agobiados o ciertamente desanimados por la multitud de temas y desistir de lo que han comenzado o desesperarse de poder dominar ** la materia perfectamente. Someto, pues, a vuestro juicio prudente y más maduro el quehacer -aceptado ciertamente con resignación [aequo certe animo... susceptum], testimonio de un espíritu que os es agradecido- y lo quiero dedicar a vuestra dignidad.

Y si noto que la benevolencia de que estáis dotados aprueba nuestros esfuerzos, perseguiré todo lo que falta con igual y (si fuera poble) mayor diligencia.

A LOS ESTUdiantes de LAS ARTES LIBERALES DE LA MUY FLORECIENTE UNIVERSIDAD DE ALGALÁ

Jóvenes estudiosos:

Volved ahora a recibir contenido en pocas palabras lo que antes tratamos más abundante y copiosamente. Brindamos lo que habéis pedido, aun más, apetecido hace tiempo, lo que vuestra universidad alcalaína ha aprobado, acogido con gusto, y juzgado cónsono con la doctrina de Aristóteles y Santo Tomás. Ojalá corresponda a nuestros deseos lo que nos esforzamos por conseguir con labores ya tomadas y por tomar. Ni tengo otra intención igual a la de serviros continuamente lo mejor que puedo ${ }^{*}+$

* A10: ut sic; C15: ut.

$\dagger$ C15: nihilo magis ferme nostrum; A10: sin magis.

* C15: se assequi; C10: sin se.

* $\dagger$ C15: maxime; Al0: omite. 
(como exige la Ratio y la regla de nuestra profesión). Tal es el propósito de nuestras labores, tal es su fin.

Gozad, pues, gustosos de nuestra diligencia y trabajo (ojalá útil). Habéis de recibir en adelante todo lo demás, con tal que esté presente el Numen divino. Adiós. 